This item was submitted to Loughborough's Research Repository by the author.

Items in Figshare are protected by copyright, with all rights reserved, unless otherwise indicated.

\title{
Exploring factors influencing the effectiveness of explicit instruction first and problem-solving first approaches
}

PLEASE CITE THE PUBLISHED VERSION

https://doi.org/10.1007/s10212-019-00445-5

PUBLISHER

Springer

VERSION

AM (Accepted Manuscript)

\section{PUBLISHER STATEMENT}

This is a post-peer-review, pre-copyedit version of an article published in European Journal of Psychology of Education. The final authenticated version is available online at: https://doi.org/10.1007/s10212-019-00445-5

\section{LICENCE}

CC BY-NC-ND 4.0

\section{REPOSITORY RECORD}

Chen, Ouhao, and S Kalyuga. 2019. "Exploring Factors Influencing the Effectiveness of Explicit Instruction First and Problem-solving First Approaches". Loughborough University. https://hdl.handle.net/2134/12052707.v1. 
Exploring Factors Influencing the Effectiveness of Explicit Instruction First and Problem Solving First Sequences 


\begin{abstract}
Problem solving followed by explicit instruction, as suggested by Productive Failure and several other instructional theories, indicates long-term learning benefits, whereas explicit instruction followed by problem solving has been consistently demonstrated as superior within the framework of Cognitive Load Theory. However, the effectiveness of these instructional approaches may be moderated by several factors such as levels of element interactivity of learning materials, types of knowledge involved, and levels of learner prior knowledge (expertise). This review systematically searched studies comparing these alternative sequences, computed the observed effect sizes, and explored the effects of element interactivity, types of knowledge, and levels of expertise on the effectiveness of two instructional approaches.

Keywords: Explicit Instruction and Problem Solving, Cognitive Load Theory, Element Interactivity, Conceptual and Procedural Knowledge, Expertise.
\end{abstract}




\section{Exploring Factors Influencing the Effectiveness of Explicit Instruction First and Problem Solving First Sequences}

The explicit instruction followed by problem solving sequence has been well documented to be superior to problem solving followed by explicit instruction design within the framework of Cognitive Load Theory (Authors, 2015, 2016a, 2016b; Cooper \& Sweller, 1987; Sweller \& Cooper, 1985). By contrast, the opposite effect has been demonstrated on many occasions within the frameworks of Productive Failure (Kapur, 2008, 2012, 2014) or Invention Learning (Schwartz \& Bransford, 1998; Schwartz, Chase, Oppezzo, \& Chin, 2011; Schwartz \& Martin, 2004). Thus, the published studies, comparing these two sequences, have generally indicated inconsistent results. This paper systematically reviews these studies in search for the patterns and conditions under which each of the two sequences is superior.

In this review, problem solving is generally considered, from a cognitive point of view, as a process involving 1) constructing the initial mental representation of the problem (including the initial and goal states), 2) planning suitable procedures for solving the problem (i.e., moving from the initial to the goal state), and then 3) executing the procedures and checking the results (e.g., Qin, Johnson, \& Johnson, 1995). The actual problem solving process depends on the levels of learner expertise. The above three stages of problem solving are usually followed meticulously only by novice learners who do not have relevant and complete domain knowledge structures (schemas) and need to search for solution moves. More knowledgeable (expert) problem solvers usually retrieve their available relevant organized knowledge structures (schemas) to rapidly categorize the problem situations and select the appropriate solution moves.

\section{Problem Solving First Sequence (PS-I)}


Problem solving first sequence (such as a problem solving task followed by a worked example or another form of direct instruction) combines a problem solving phase and an explicit instruction phase. The effectiveness of using this sequence has been investigated in a large number of studies (e.g., Jacobson, Markauskaite, Portolese, Kapur, Lai \& Roberts, 2017; Kapur, 2012, 2014; Lai, Portolese, \& Jacobson, 2017; Loibl \& Rummel, 2014a, 2014b; Schalk, Schumacher, Barth, \& Stern, 2017). During the problem solving phase, novices (i.e., learners who does not have relevant schemas) are asked to solve problems related to novel concepts and procedures that they have not yet been taught. The learners' performance during the problem solving phase is usually very poor, frequently resulting in failures (Kapur, 2010, 2012). During the following explicit instruction phase, teachers start with comparing student-generated answers, then consolidate strategies used during the problem solving phase, and provide the canonical solution. This structure is common to all problem solving first approaches. This approach has been reported as especially effective for teaching conceptual knowledge and enhancing the learner ability to transfer (Loibl, Roll \& Rummel, 2017).

From a cognitive perspective, several reasons have been suggested to explain the potential effectiveness of PS-I approach (Loibl et al., 2017):

Activation of Prior Knowledge. An agreed function of the problem solving phase of PS-I is to activate participants' prior knowledge in order to invent/generate the solutions and strategies for solving the new problems (Kapur \& Bielaczyc, 2012). The activated prior knowledge makes it easier to integrate new information with the available knowledge base (Schmidt, De Volder, De Grave, Moust \& Patel, 1989; Schwartz, Sears \& Chang, 2012; Toh \& Kapur, 2017). As participants have not been formally taught concepts for solving the new problems, the generated solutions and strategies may be incorrect and naïve based on 
participants' intuitive ideas, however, the generation process may have provided more resources for the long-term successful learning (Kapur \& Bielaczyc, 2012). The function of activating learner prior knowledge has been supported by several PS-I studies (Kapur, 2014; Roll, Aleven \& Koedinger, 2011).

Awareness of Knowledge Gap. Chi (2000) suggested that students' initial mental models are different from the normative ones, and they can only repair their mental model when they are aware of the flaws. Similarly, the impasse-repair-reflect process (VanLehn, 1999) suggests that when students reach an impasse, they will apply solutions and strategies to repair the impasse. Therefore, correct and professional solutions could be processed only when students are aware of the knowledge gaps and impasses (VanLehn, Siler, Murray, Yamauchi \& Baggett, 2003). PS-I approaches could facilitate students' awareness of their knowledge gaps in two ways: by providing some contrasting cases for students making predictions (Roll, Holmes, Day \& Bonn, 2012) and by consolidating students' common incorrect solutions before proving correct and professional solutions (Loibl \& Rummel, 2014).

Recognition of Deep Features. Kapur and Bielaczyc (2012) suggested that the productive failure design (one of PS-I designs) allows students to identify, explain and organize the deep features of targeted knowledge. It could be achieved by two suggested ways: using contrasting cases (Roll et al., 2012) and comparing non-correct students' solutions to each other or with correct and professional solutions (Kapur 2012; Loibl \& Rummel, 2014). Also, highlighting the deep features of the targeted knowledge during instruction phase followed by problem solving was found to be less effective than addressing the deep features during the problem solving phase followed by identical instruction (Loibl et al., 2017). 
Besides the above cognitive considerations, other aspects may also potentially influence the effectiveness of PS-I approach, such as learner motivation (Glogger-Frey, Fleischer, Grüny, Kappich \& Renkl, 2015; Belenky \& Nokes-Malach, 2012) and collaborative or individual learning (Sears, 2006; Westermann \& Rummel, 2012). Students with higher levels of motivation may be more engaged in initial problem solving activities prior to instruction compared to students with lower levels of motivation, which shows a clear direction in how motivation may influence the effectiveness of PS-I approach. Even though some studies that demonstrated the advantages of this approach used collaborative learning settings in the initial problem solving phase (e.g., Kapur, 2008; Kapur \& Bielaczyc, 2012), it is not yet possible to definitely specify in what direction the collaborative or individual learning can influence the effectiveness of PS-I approach, and more studies are required.

The above features have not only been used to explain the effectiveness of PS-I approaches in preparing learners to face complex tasks, but also set out some rules for designing the learning materials/problems used in PS-I approaches. The most frequently investigated particular implementation of PS-I approach is the Productive Failure method.

\section{Productive Failure}

Productive Failure is regarded as an effective instructional method for problem-based learning (Kapur, 2008; Darabi, Arrington, \& Sayilir, 2018). The general design includes 1) generation and exploration phase: learners are required to self-solve the presented problems without any instruction, even though they may feel frustrated, struggle and then fail; 2) consolidation phase: teachers respond to learners' solutions/strategies and provide professional solutions (Kapur, 2016). Also, Kapur (2016) suggested some criteria for designing Productive Failure problems: firstly, the problems must be understandable for learners who are novices; 
secondly, the problems should allow learners to draw on their prior knowledge and apply multiple strategies; and lastly, the problems should involve a kind of challenge.

The effectiveness of Productive Failure has been explained from both cognitive and motivational perspectives. From the cognitive perspective, firstly, the generation and exploration phase could activate students' prior knowledge and help them to find out their knowledge gaps, which reflects the findings of Loibl et al., 2017; secondly, as students have attempted to generate the solutions themselves, the canonical solution presented at the following consolidation phase could be compared with self-generated solutions, enabling students to pay attention to the critical features of the teacher-provided solution and recognize the deep features of targeted knowledge (Loibl et al., 2017); from the motivational perspective, exploration and generation phase may better engage students and motivate them to learn (Kapur, 2016). Also, the explicit instruction first may interfere with implicit learning (Reber, 1989), which may make learners unaware of the situational structures that make the procedures effective (Schwartz, Lindgren, \& Lewis, 2009).

\section{Explicit Instruction First Sequence (I-PS)}

Explicit instruction first sequence (such as a worked example or another form of direct instruction followed by a problem solving task) provides comprehensive guidance before problem solving. For example, participants study a worked example, including a full set of procedural steps, of the targeted problem, followed by solving a similar problem. This sequence is grounded under the framework of cognitive load theory.

Cognitive Load Theory. Cognitive load theory, the theoretical base of I-PS, suggests that for novice learners, explicit instruction first followed by problem solving is superior to the reversed order suggested by alternative framework. Cognitive load theory is an instructional 
theory, which is based on the human cognitive architecture (for a comprehensive overview, see Authors, 2011). Two major components of this architecture are working memory and long-term memory. Working memory has very limited capacity (Cowan, 2001; Miller, 1956) and limited duration (Peterson \& Peterson, 1959) - it cannot process more than a few units of information at a time (3-5 is a realistic estimate) or hold them for longer than 10-20 seconds. Long-term memory, on the other side, has unlimited capacity and duration in holding organized knowledge structures (schemas). When relevant schemas stored in long-term memory are activated and transferred to working memory, the effective working memory capacity can be substantially increased by encapsulating many elements of information into a small number of chunks based on those schemas (Ericsson \& Kintsch, 1995).

\section{Worked Example Effect}

The most common implementation of the I-PS approach is associated with the worked example effect and the use of worked example-problem solving pairs. Cognitive load theory provides compelling reasons for the superiority of the worked examples over unguided problem solving for novice learners. During the explicit instruction (worked example phase), learners borrow the knowledge from worked examples rather than self-generate solutions by themselves. The self-generation of problem solutions in the absence of relevant schemas is very effortful process for novice learners, as it requires significant working memory resources leading to a potential cognitive overload. Providing the required schemas explicitly first in worked examples significantly reduces this irrelevant to learning (extraneous) cognitive load (worked example effect: Sweller et al., 2011; Sweller, Merrienboer \& Pass, 1998). After learning a worked example, a similar problem is presented for solving (the problem solving phase). In order to learn from the worked example meaningfully, novices may also need conceptual knowledge relevant 
to the task domain to aid the learning of the required procedural knowledge. A great number of empirical studies over many years have provided strong evidence to support this example-first approach (starting from Cooper \& Sweller, 1987 and Sweller \& Cooper, 1985 up to the recent studies by Author et al., 2015, 2016a, 2016b).

Several reported experiments compared worked example-problem solving with problem solving-worked examples sequences, that varied only the order of instructions (Authors, 2015; Leppink, Paas, Van Gog, van Der Vleuten, \& Van Merrienboer, 2014; Van Gog, Kester, \& Paas, 2011). Although, the studies of Leppink et al. (2014) and Van Gog et al. (2011) were designed for other reasons than specifically comparing these alternative approaches, all the above studies consistently supported the advantage of explicit instruction first. There were also a number of other studies with no productive failure effect or with a reversed effect supporting the explicit instruction first sequence (Fyfe, DeCaro, \& Rittle-Johnson, 2014; Rittle-Johnson, Fyfe, \& Loehr, 2016).

However, the superiority of the explicit instruction first approach, as implied by the worked example effect in cognitive load theory may be moderated by the levels of element interactivity of learning materials and the levels of learner expertise (Authors, 2018).

\section{Element Interactivity and Expertise}

Element interactivity is the central concept of Cognitive load theory, which is used to differentiate the levels of difficulty of learning materials. It refers to the number of interconnected elements in a learning task that must be processed simultaneously in working memory for meaningful learning. For example, the task of memorizing two English words, such as cat and $d o g$, belongs to materials low in element interactivity, as these two words could be 
memorized individually, and they are not interconnected elements. This task is easy as it does not demand much of the limited working memory capacity. Whereas, when solving an equation, such as $5 x+6=11$, the elements $(5, x,+, 6,=, 11)$ must be processed simultaneously rather than individually in working memory, otherwise learners would not be able to understand the relations among those elements and successfully search for the solution. Therefore, the task of solving an equation belongs to materials high in element interactivity compared to the task of memorizing separate English words. This task could be difficult to learners, as it might demand more cognitive resources that the available limited working memory capacity (which is in the range of $3-5$, as mentioned above).

Evidence has shown that explicit instruction first may only be effective when learning relatively difficult materials that are high in element interactivity rather than materials low in element interactivity. For example, Author et al. (2015, 2016a, 2016b) designed a series of experiments to test this hypothesis in the domain of mathematics. Secondary school students were randomly assigned to generation and presentation conditions. Students in the generation condition generated geometric formulas by themselves, whereas, students in the presentation condition were presented the formulas to read. Memorizing a formula belongs to materials low in element interactivity (students could memorize each symbol of this formula separately), and the results demonstrated the superiority of the generation condition. However, for the following task of applying those memorized formulas to solving relevant math problems (materials high in element interactivity), the superiority of explicit instruction (presenting worked examples first) was found over problem solving (generation) first. Therefore, explicit instruction first followed by problem solving may be an effective instructional sequence only for materials high in element interactivity (Author et al., 2011). 
A learning task that involves many interactive elements for novice learners (a high element interactivity task) could present just a few elements for more knowledgeable (expert) learners due to available schemas in their long-term memory that would allow them to incapsulate may elements in a single unit. For example, the above equation $5 x+6=11$ could involve one or two elements for these learners allowing them to almost immediately come up with a solution. Therefore, the levels of element interactivity are not fixed and absolute values but are always relative to expertise of the learners. As levels of element interactivity and the levels of learner expertise are closely associated, the change in the levels of expertise may affect the levels of element interactivity resulting in an expertise reversal effect (Authors, 2017).

According to the expertise reversal effect, instructional methods that are effective for novices, might be harmful for more knowledgeable learners (Author, 2007). When this principle is applied to the explicit instruction vs. problem solving instructional approaches, presenting worked examples first followed by problem solving should result in better outcomes for novices than the problem solving first followed by worked examples (worked example effect). However, the reversed results were found for more knowledgeable learners (Authors, 2001). When novices learn new materials, the levels of element interactivity are high for them, therefore, the most effective way of learning such materials is to use explicit instruction first followed by problem solving. However, when the levels of learner expertise in the task domain are increased, the materials become low in element interactivity, rendering the reversed effect with the problem solving first sequence as more effective (Author et al., 2015, 2016a, 2016b).

\section{Conceptual Knowledge vs. Procedural Knowledge}

In a domain, such as mathematics, two major types of knowledge are traditionally discussed: conceptual knowledge (knowledge of classifications and categories, principles and 
generalizations, theories, models, and structures) and procedural knowledge (knowledge of subject-specific skills and algorithms, techniques and methods) (e.g., Anderson \& Krathwohl, 2001). The procedural knowledge is usually considered as implicit, automated action sequences for problem solving (Rittle-Johnson \& Alibali, 1999), such as sequential steps of solving a math equation, whereas, the definition of conceptual knowledge lacks consistency (Crooks \& Alibali, 2014). It is mostly considered as general principle knowledge (understanding the principles that govern a domain), such as knowing a math category or theorem, or knowledge of principles underlying procedures (knowing why a procedure works), such as understanding the formula of $\mathrm{NaCl}$ for sodium chloride, which involves understanding the procedures for combining $\mathrm{Na}^{+}$and $\mathrm{Cl}^{-}$. Also, when we consider conceptual vs. procedural distinction solely within the dimension of declarative knowledge, they both are explicit types of knowledge, i.e., declarative knowledge about concepts and declarative knowledge about procedures (sequences of steps). While problem solving models do not vary based on this distinction, it is important that learning different types of knowledge may involve different cognitive processes.

Most of research studies of problem solving first approach (PS-I) indicated its superiority for learning conceptual knowledge (Loibl \& Rummel, 2014; DeCaro \& Rittle-Johnson, 2012; Kapur, 2014; Loibl et al., 2017), whereas, most of studies of explicit instruction first approach (IPS) suggested its superiority for learning procedural knowledge (Sweller \& Cooper, 1985; Cooper \& Sweller 1987; Author et al., 2015; Van Gog et al., 2011).

\section{Present Study and Research Questions}

The present study aims to explore the effect of three factors, element interactivity, expertise and types of knowledge, on PS-I vs. I-PS sequences. For the element interactivity factor, it is necessary to estimate the levels of element interactivity of each specific learning task 
used in the reviewed experiments by evaluating the number of interactive elements that need to be processed simultaneously in working memory at a given time. The existing research studies of I-PS approach in cognitive load theory have usually assessed the levels of element interactivity of experimental materials, however, most of the studies of PS-I approach have not assessed element interactivity (and hardly even mentioned this concept itself). According to Author et al. $(2015,2016 a, 2016 b)$, the factor of element interactivity may be critical for clarifying the conditions under which PS-I or I-PS approaches may be effective. Therefore, it may be necessary to also assess the levels of element interactivity of tasks used by PS-I studies. As a part of the review process, this study evaluated the levels of element interactivity of all the materials used in both PS-I and I-PS studies that had been included in the analysis.

For the expertise factor, in cognitive load theory, I-PS is regarded to be effective for novices, but this effect may be reversed when expertise is increased, indicating the expertise reversal effect (Author, 2007). Whereas, research in productive failure framework has indicated that expertise might not influence its effectiveness (Toh \& Kapur, 2017). However, no general conclusions are found about how expertise may affect PS-I designs. Therefore, this study also aims to explore if there is a stable general pattern of relation between expertise and the effectiveness of PS-I approach.

For types of knowledge, Loibl et al., (2017) concluded that PS-I approach was consistently found to be effective in facilitating learning conceptual knowledge, while I-PS approach was more likely to be effective for learning procedural knowledge (Sweller \& Cooper, 1985; Cooper \& Sweller 1987; Author et al., 2015; Van Gog et al., 2011). However, there are different types of conceptual knowledge, such as general principle knowledge and knowledge of principles underlying procedures (Crook \& Alibali, 2014). Therefore, another aim of this study is 
to categorize PS-I studies based on specific types of conceptual knowledge involved rather than on its general definition.

\section{Method}

In order to explore for possible patterns of effects of the above factors (element interactivity, expertise and types of knowledge), the available research studies comparing I-PS and PS-I approaches were systematically searched and the relevant studies categorized based on the three selected factors (see Table 1 for a summary).

[Table 1 may be inserted here]

\section{Participants}

Overall, there were over 3000 participants involved in the reviewed studies. According to Table 1, majority of the participants were novices or had low level of prior knowledge in specific domains of the studies. Also, participants represented various levels of education (primary school, secondary school and university), different races and ages.

\section{Inclusions and Exclusions of Study}

To systematically search for relevant studies, two major databases were used, Web of Science and EBSCOhost. In each database, the keywords Productive Failure AND Prior Knowledge were used for the first round of search, then the keywords Invention Learning AND Prior Knowledge were used for the second round of search, followed by the keywords Problem Solving Prior to Instruction AND Prior Knowledge for the third round of search. For Web of Science, there were 20 studies found in the first round of search, 31 studies for the second round of search and 186 studies found in the last round of search, whereas for EBSCOhost, there were 
20, 25 and 28 studies found for the first, second and third rounds of search respectively. There were five studies added manually (these studies had not been detected by searching the two databases with the selected keywords, but they were found by going through the references of the detected studies).

The following three principles were used to select studies for inclusion: 1) the study must be empirical/experimental study comparing explicit instruction first (I-PS) with problem solving first (PS-I) instructional sequences; 2) the report should provide enough statistics, such as $F$ value, for computing effect size (Cohen's $d$ was used as the indicator of effect size for all included studies); 3) the study must include formal assessments of performance using post-tests (studies that involved only measures of learner performance during learning phases were not included). The comparisons of PS-I vs. I-PS sequences were all based on post-test performance measures. Based on these selection principles and after deleting duplicated studies from the three-round search, there were 23 studies finally included in the analysis. The excluded studies were either not empirical/experimental studies or measured motivation rather than performance; some studies did not compare the two alternative sequences (PS-I vs. I-PS), but rather compared worked examples only with problem solving tasks only, or made comparisons among various types of problem solving approaches.

\section{Descriptions of Included Studies}

For the included studies, the following seven indicators were used to analyze each study (see Table 1): 1) authors' information and publication year of the study; 2) effect size for compared instructional sequences; 3) study type (e.g., journal article or dissertation); 4) type of knowledge (conceptual or procedural); 5) levels of element interactivity of learning materials (low or high); and 6) levels of prior knowledge (low, high, or not measured). 


\section{Computing Effect Size}

In this study, all the final effect sizes for analysis were Cohens' $d$. For studies using etasquared values, these values were converted to the Cohen's $d$ by using an online computing tool (https://www.psychometrica.de/effect_size.html). Positive effect sizes showed effects supporting problem solving first instructional sequences (PS-I), while negative effect sizes showed effects supporting explicit instruction first instructional sequences (I-PS). The cut-out points for small, medium and large effects were $0.2,0.5$, and 0.8 respectively. Once Cohen's $d$ of each selected study had been calculated, the mean effect size (negative value) of studies supporting explicit instruction first (I-PS) and the mean effect size (positive value) of studies supporting problem solving first (PS-I) were calculated separately.

\section{Assessing the Levels of Element Interactivity}

The levels of element interactivity were evaluated by estimating the number of interactive elements that need to be potentially processed simultaneously in learner working memory at a given time when learning the given material.

Materials with High Levels of Element Interactivity. DeCaro and Rittle-Johnson (2012) used math problems of gradually increased difficulty, such as $10=3+\square$ (the easiest level), to teach children the concept of equivalence. The estimated number of interactive elements would be 5 , as learners need to process five elements $(10,=, 3,+$ and $\square)$ simultaneously when solving for the number in the box. The similar learning tasks were used in the studies of DeCaro, DeCaro and Rittle-Johnson (2015), Fyfe, DeCaro and Rittle-Johnson (2014) and Loehr, Fyfe and RittleJohnson (2014). 
Schwartz, Chase, Oppezzo and Chin (2011) required students to invent a general index for crowdedness representing the concept of density. This task required learners to simultaneously consider the value of an index (as a goal), the suggested narrative for finding a crowdedness index (around five estimated elements), and the rule for the crowdedness index as concept of density (estimated three elements). Similar materials were used in the studies of Glogger-Frey, Fleischer, Grüny, Kappich and Renkl (2015) and Weaver, Chastain, DeCaro and DeCaro (2018).

Kapur $(2012,2014)$ required students to invent as many solutions as possible to mathematically determine the most consistent player, by comparing the scores of the top two players, as a way of learning the concept of variance. As there were 20 scores for each player, in order to evaluate the consistency, students had to consider all 20 scores of a player simultaneously, rendering at least 20 interactive elements. The similar materials were used in the studies of Loibl and Rummel (2014a; 2014b), Cook (2017), Kapur (2010), Kapur and Bielaczyc (2011).

Dubovi (2018) used a simulated clinic scenario (real-life cases). For example, participants were given a complex scenario of a pregnant woman with mood disorder and required to make decisions about her physical and mental condition, as well as the health of her baby. The presented scenario required participants to generate knowledge within and across multiple domains, without explicitly defining them. Jacobson et al. (2017) used challenging problems on climate models and complex system models involving multiple factors affecting climate (such as greenhouse effect or wind), rendering the learning materials with high levels of element interactivity. 
Kapur (2011) and Kapur and Bielaczyc (2012) designed complex mathematical problems involving the concepts of average speed and the lowest common multiples. Author et al. (2015) required students to apply conservation of energy and momentum principles to solve complex physical problems involving colliding physical objects, and multiple parameters such as time, speed and distance. These tasks involved multiple steps with many interactive elements, generating high levels of element interactivity. Van Gog et al. (2011) used learning tasks on troubleshooting electrical circuits that required participants to diagnose the fault by performing multiple steps, such as calculating the current, and comparing the actual measures with calculated ones - the tasks with high levels of element interactivity.

Materials with Low Levels of Element Interactivity. The materials used by GloggerFrey, Gaus and Renkl (2017) turned out to be low in element interactivity due to additional practice that increased the levels of learner expertise. Lai, Portolese and Jacobson (2017) recruited knowledgeable learners with high levels of expertise, making the levels of interactivity for learning materials low.

\section{Results and Discussion}

Ten out of 23 studies indicated the superiority of explicit instruction first sequence on the post-test. The mean effect size was $d=-0.63$ (medium to large), indicating that the advantage of explicit instruction first approach was robust across analyzed studies.

Fifteen out of 23 studies indicated the superiority of problem solving first sequence on the post-test. The mean effect size was $d=0.96$ (large), indicating that the superiority of the problem solving first sequence was robust across analyzed studies. There is an overlap in the 
above number of studies, as two included research studies indicated superiority of both sequences (in different experiments).

Conceptual Knowledge. According to Table 1, there were 17 studies investigating the conceptual knowledge. 15 out of 17 research studies tapping on conceptual knowledge demonstrated the superiority of the problem solving first sequence (PS-I) compared to the explicit instruction first sequence (I-PS). Only Fyfe et al. (2014) and Loehr et al. (2014) found the superiority of the explicit instruction first sequence (I-PS) for learning conceptual knowledge in the domain of mathematics. Therefore, problem solving first instructional sequence (PS-I) was in most cases more effective for learning conceptual knowledge.

Procedural Knowledge. Concerning the results for procedural knowledge, the explicit instruction first sequence (I-PS) was consistently more effective. There was only one study by Loehr et al. (2014) that found the superiority of the problem solving first sequence (PS-I) on learning procedural knowledge. However, the validity of this result could be questioned as over $50 \%$ of participants could correctly solve all the items, indicating that the data could be skewed (Loehr et al., 2014).

Element Interactivity. Based on our estimates of levels of element interactivity of learning materials for the included studies, all materials used for teaching procedural knowledge were classified as high in element interactivity. Most of the materials used for teaching conceptual knowledge appeared to be also relatively high in element interactivity, with only a few exceptions in which low levels of element interactivity were due to high levels of learner expertise. 
According to Table 1, for low element interactivity materials, all the available (although very limited) evidence supported the superiority of problem solving first instruction (PS-I), whereas, for higher element interactivity tasks, I-PS approach was found more effective for learning procedural knowledge, while PS-I approach was found more effective mostly for learning conceptual knowledge. These results partially contradict some traditional assumptions of cognitive load theory and warrant further discussion.

According to Crooks and Alibali (2014), it is possible to distinguish different types of conceptual knowledge. The conceptual knowledge of low element interactivity could be potentially associated with what they call general principle knowledge - the knowledge that is not closely tied to any specific procedures, such as when students are required to memorize some general rules or definitions (e.g., the equal sign means "the same as"). For many common concepts (such as the concepts of area, length, height, weight, etc.), this general principle knowledge may have good intuitive sense that may be related to biologically primary knowledge in evolutionary educational psychology (Geary, 2002) - the type of evolutionary-predisposed knowledge we usually learn implicitly. However, the conceptual learning materials with relatively higher levels of element interactivity, that had been involved in the experiments used for comparing the PS-I with the I-PS sequences in this review, required students to generate significant amounts of procedure-related information. This type of conceptual knowledge is referred to as knowledge of principles underlying procedures by Crooks and Alibali, (2014), which is closely associated with specific procedures. The demonstrated superiority of problem first sequences (PS-I) for learning this relatively high-interactivity conceptual knowledge may contradict traditional views of the worked example effect in cognitive load theory which assumes explicit instruction first sequence (I-PS) to be superior for all high element interactivity tasks. 
There are two possible ways to resolve this contradiction. Staying within the traditional framework of cognitive load theory, it is possible to contemplate that when learning conceptual knowledge of high element interactivity, a problem-solving attempt prior to explicit instruction (even if the learners fail to solve the problem) may familiarize them with some important elements of the task, although in isolated form without seeing all the essential and meaningful connections or interactions with other elements. Such preliminary elementary learning might reduce the potentially heavy working memory load that could otherwise be experienced during the comprehensive explicit instruction in complex concepts. In the framework of cognitive load theory, this method is known as the isolated-interactive elements effect (Author et al., 2011). It is based on an artificial reduction or simplification of complex relations between essential elements of information during the initial phase of learning, which may help learners to acquire some relevant partial schemas in an isolated form, followed by the comprehensive instruction in the next phase, which aims at the acquisition of the complete and correct schemas (similar to the consolidation phase in the productive failure approach).

As to why the problem-first approach would work with conceptual but not procedural knowledge of high element interactivity, a possible answer could be that worked examples of a procedure significantly reduce working memory load by focusing learner attention on one problem state at a time and showing the appropriate solution step for this state. Whereas, explicit instruction in complex conceptual knowledge may not be able to achieve a significant reduction of cognitive load in this manner and thus, may benefit from a preliminary exposure of learners to only some of the essential conceptual elements (in the isolated format) during their initial problem-solving attempts. 
For delineating another possible way of resolving the above contradiction, it should be noted that, in accordance with traditional framework of cognitive load theory, the implicitly assumed goal of instruction is learning domain-specific solution schemas for various categories of problem situations. However, in a recent addition to this theory (Author, 2016), it was suggested that other types of specific instructional goals might need to be considered for some learner activities within complex learning tasks, for example, activating learners' prior knowledge, motivating and engaging them, or setting appropriate emotional states (Author, 2019). This suggestion allows to explain the observed in some situations effectiveness of problem solving first approaches (such as productive failure method) for novice learners by associating the first (problem-solving, exploratory or generation) phase of learning with such alternative goals.

In fact, the existing theories of productive failure and other problem-first approaches (as reviewed at the beginning of this paper) are in agreement with this interpretation of learning goals. Within this goal-based framework, the effectiveness of particular sequences of explicit instruction and problem solving in complex learning tasks would essentially be determined by the appropriateness of the sequences of specific instructional goals of comprised learning activities. The discussed pattern of superior effectiveness of the problem solving first sequence over the explicit instruction first sequence for learning conceptual knowledge may indicate the need to apply this goal-based approach and consider other types of goals that are different from the goal of learning domain-specific solution schemas (knowledge about procedures) associated with the traditional framework of cognitive load theory.

Levels of Expertise. Considering the information in Table 1, and the closed (essentially, inverted) relation between the levels of element interactivity and levels of expertise, for novices 
(for whom the tasks were of higher level of element interactivity), the explicit instruction first sequences (I-PS) showed superiority for teaching procedural knowledge, whereas, the problem solving first sequences (PS-I) showed superiority for teaching conceptual knowledge. For learners with higher levels of prior knowledge (for whom the tasks were of low levels of element interactivity), there were only two studies available for analyses, Glogger-Frey et al. (2017) and Lai et al. (2017), and they both indicated that the problem solving first sequences (PS-I) were more effective.

\section{Conclusion}

This paper systematically searched for and reviewed studies comparing the order of explicit instruction and problem solving to explore for possible stable patterns of relationships between their effectiveness and a number of candidate factors. The analysis showed that both instructional sequences, explicit instruction first (I-PS) and problem solving first (PS-I), were effective. When specific factors, such as types of knowledge, levels of element interactivity and levels of learners' expertise, were taken into account, some conditions of effectiveness could be articulated for each of the above sequences.

For types of knowledge, the problem solving first sequence (PS-I) was found to be an effective instructional procedure for learning conceptual knowledge, specifically, knowledge of principles underlying procedures, whereas, learning knowledge about procedures was more effective using the explicit instruction first (I-PS) approach. The type of conceptual knowledge about general principle knowledge was not used in the reviewed studies. Further research studies are required to compare PS-I and I-PS sequences for conceptual knowledge of different types. 
Concerning the effect of levels of element interactivity of materials, the results depended on the types of knowledge. For procedural knowledge, the classical assumption of cognitive load theory was supported: I-PS approach was superior for high element interactivity tasks. For conceptual knowledge, the two types of this knowledge may need to be considered - general principle knowledge and knowledge of principles underlying procedures. The reviewed studies used only the second type of conceptual knowledge (knowledge of principles underlying procedures which is high in element interactivity), and for both high and low (due to higher expertise of learners) levels of element interactivity, the problem first (PS-I) sequence was superior to the reverse sequence.

The Importance and Niche of This Study. This review summarized how the three major relevant factors, types of knowledge, levels of learner expertise and levels of element interactivity, affected the effectiveness and relations between PS-I and I-PS approaches, which could open new avenues of research in comparing these instructional approaches using multifactorial methods. Also, this study integrated the traditional worked example-problem solving and problem solving-worked example sequences into the corresponding broader classes of I-PS and PS-I approaches.

Educational Implications. An important educational implication of this study is that when designing or selecting the learning tasks using PS-I or I-PS approach for classroom teaching, it is necessary to consider levels of learner expertise, the nature of learning materials, and the types of knowledge to be learned. In addition, the learners and learning materials should be approached dynamically, as with increases in levels of learner expertise, the difficulty (levels of element interactivity) of learning materials will be decreased, and the optimal approaches used in instructional design would need to be revised accordingly. 
Limitations of This Study. Due to a very limited number of available studies that have investigated the influence of expertise on the effectiveness of PS-I and I-PS approaches, we still have no conclusive idea on whether the levels of learner expertise would moderate the effectiveness of the problem solving first (PS-I) approach with conceptual knowledge, and further investigation into this issue is needed as well.

The best possible form of instructional design always depends on the specific learning tasks and their goals, and uncovering the factors influencing the selection of optimal designs is the ultimate aim of the review studies such as this. The conclusions of this review are based on a limited number of the detected published empirical studies that have investigated the alternative sequences involving problem solving and explicit instruction learning tasks. As far as we understand the pattern emerging within this limit, PS-I approach works well for conceptual knowledge, while I-PS approach works better for procedural knowledge. However, we cannot conclude with certainty that these designs are optimal (or even possible) for any conceptual or procedural element of knowledge, as no reviews have sorted out or empirical studies experimented with all types of conceptual or procedural knowledge. More research comparing these two approaches with different type of knowledge is required. 


\section{References}

(* shows studies included in this review)

Authors (2015)

Authors (2016a)

Authors (2016b)

Authors (2017)

Authors (2019)

*Authors (2015).

Author (2007).

Authors (2001).

Authors (2016).

Authors (2019).

Authors (2011).

Anderson, L. W., Krathwohl, D. R. (Eds..) (2001). A Taxonomy for Learning, Teaching, and Assessing: A Revision of Bloom's Taxonomy of Educational Objectives. Boston, MA: Allyn \& Bacon.

*Chase, C. C., \& Klahr, D. (2017). Invention versus direct instruction: for some content, it's a tie. Journal of Science Education and Technology, 26, 582-596. doi: 10.1007/s10956017-9700-6

Chi, M. T. H. (2000). Self-explaining expository texts: the dual processes of generating inferences and repairing mental models. In R. Glaser (Ed.), Advances in instructional psychology (pp. 161-238). Hillsdale: Lawrence Erlbaum Associates. 
*Cook, M. (2017). A Comparison of the Effectiveness of Worked Examples and Productive Failure in Learning Procedural and Conceptual Knowledge Related to Statistics (Unpublished Doctoral Dissertation). Pennsylvania State University.

Cooper, G., \& Sweller, J. (1987). Effects of schema acquisition and rule automation on mathematical problem-solving transfer. Journal of Educational Psychology, 79, 347-362. doi: $10.1037 / 0022-0663.79 .4 .347$

Cowan, N. (2001). Metatheory of storage capacity limits. Behavioral and Brain Sciences, 24, 154-176. doi: 10.1017/S0140525X0161392X

Crooks, N. M., \& Alibali, M. W. (2014). Defining and measuring conceptual knowledge in mathematics. Developmental Review, 34, 344-377. doi: 10.1016/j.dr.2014.10.001

Darabi, A., Arrington, T.L., \& Sayilir, E. (2018). Learning from failure: a meta-analysis of the empirical studies. Educational Technology Research and Development, 66, 1101-1118. doi: $10.1007 / \mathrm{s} 11423-018-9579-9$

*DeCaro, D. A., DeCaro, M. S., \& Rittle-Johnson, B. (2015). Achievement motivation and knowledge development during exploratory learning. Learning and Individual Differences, 37, 13-26. doi: 10.1016/j.lindif.2014.10.015

*DeCaro, M. S., \& Rittle-Johnson, B. (2012). Exploring mathematics problems prepares children to learn from instruction. Journal of Experimental Child Psychology, 113, 552-568. doi: 10.1016/j.jecp.2012.06.009

*Dubovi, I. (2018). Designing for online computer-based clinical simulations: Evaluation of instructional approaches. Nurse Education Today, 69, 67-73. doi: 10.1016/j.nedt.2018.07.001 
Ericsson, K. A., \& Kintsch, W. (1995). Long-term working memory. Psychological Review, 102, 211-245. doi: 10.1037/0033-295X.102.2.211

*Fyfe, E. R., DeCaro, M. S., \& Rittle-Johnson, B. (2014). An alternative time for telling: When conceptual instruction prior to problem solving improves mathematical knowledge. British Journal of Educational Psychology, 84, 502-519. doi: 10.1111/bjep.12035

Geary, D. C. (2002). Principles of evolutionary educational psychology. Learning and individual differences, 12, 317-345. doi: 10.1016/S1041-6080(02)00046-8

*Glogger-Frey, I., Fleischer, C., Grüny, L., Kappich, J., \& Renkl, A. (2015). Inventing a solution and studying a worked solution prepare differently for learning from direct instruction. Learning and Instruction, 39, 72-87. doi: 10.1016/j.learninstruc.2015.05.001

*Glogger-Frey, I., Gaus, K., \& Renkl, A. (2017). Learning from direct instruction: Best prepared by several self-regulated or guided invention activities? Learning and Instruction, 51, 2635. doi: 10.1016/j.learninstruc.2016.11.002

*Jacobson, M. J., Markauskaite, L., Portolese, A., Kapur, M., Lai, P. K., \& Roberts, G. (2017). Designs for learning about climate change as a complex system. Learning and Instruction, 52, 1-14. doi: 10.1016/j.learninstruc.2017.03.007

Kapur, M. (2008). Productive failure. Cognition and Instruction, 26, 379-424. doi: $10.1080 / 07370000802212669$

*Kapur, M. (2010). Productive failure in mathematical problem solving. Instructional Science, 38, 523-550. doi: 10.1007/s11251-009-9093-x

*Kapur, M. (2011). A further study of productive failure in mathematical problem solving: Unpacking the design components. Instructional Science, 39, 561-579. doi: 10.1007/s11251-010-9144-3 
*Kapur, M. (2012). Productive failure in learning the concept of variance. Instructional Science, 40, 651-672. doi: 10.1007/s11251-012-9209-6

*Kapur, M. (2014). Productive failure in learning math. Cognitive Science, 38, 1008-1022. doi: $10.1111 / \operatorname{cogs} .12107$

Kapur, M. (2016). Examining productive failure, productive success, unproductive failure, and unproductive success in learning. Educational Psychologist, 51, 289-299. doi: $10.1080 / 00461520.2016 .1155457$

*Kapur, M., \& Bielczyz, K. (2011). Classroom-based experiments in productive failure. In Proceedings of the Annual Meeting of the Cognitive Science Society (Vol. 33, No. 33).

*Kapur, M., \& Bielaczyc, K. (2012). Designing for productive failure. Journal of the Learning Sciences, 21, 45-83. doi: 10.1080/10508406.2011.591717

*Lai, P. K., Portolese, A., \& Jacobson, M. J. (2017). Does sequence matter? Productive failure and designing online authentic learning for process engineering. British Journal of Educational Technology, 48, 1217-1227. doi: 10.1111/bjet.12492

Leppink, J., Paas, F., Van Gog, T., van Der Vleuten, C. P., \& Van Merrienboer, J. J. (2014). Effects of pairs of problems and examples on task performance and different types of cognitive load. Learning and Instruction, 30, 32-42. doi:

10.1016/j.learninstruc.2013.12.001

*Loehr, A. M., Fyfe, E. R., \& Rittle-Johnson, B. (2014). Wait for it... Delaying instruction improves mathematics problem solving: A classroom study. The Journal of Problem Solving, 7, 36-49. doi: 10.7771/1932-6246.1166 
*Loibl, K., \& Rummel, N. (2014a). The impact of guidance during problem-solving prior to instruction on students' inventions and learning outcomes. Instructional Science, 42, 305326. doi: 10.1007/s11251-013-9282-5

*Loibl, K., \& Rummel, N. (2014b). Knowing what you don't know makes failure productive. Learning and Instruction, 34, 74-85. doi: 10.1016/j.learninstruc.2014.08.004

Loibl, K., Roll, I., \& Rummel, N. (2017). Towards a theory of when and how problem solving followed by instruction supports learning. Educational Psychology Review, 29, 693-715. doi: $10.1007 / \mathrm{s} 10648-016-9379-\mathrm{x}$

Miller, G. A. (1956). The magical number seven, plus or minus two: Some limits on our capacity for processing information. Psychological Review, 63, 81-97. doi: 10.1037/h0043158

Peterson, L., \& Peterson, M. J. (1959). Short-term retention of individual verbal items. Journal of Experimental Psychology, 58, 193-198. doi: 10.1037/h0049234

Qin, Z., Johnson, D. W., \& Johnson, R. T. (1995). Cooperative versus competitive efforts and problem solving. Review of Educational Research, 65, 129-143.

Reber, A. S. (1989). Implicit learning and tacit knowledge. Journal of Experimental Psychology: General, 118, 219-235. doi: 10.1037/0096-3445.118.3.219

Rittle-Johnson, B., \& Alibali, M. W. (1999). Conceptual and procedural knowledge of mathematics: Does one lead to the other? Journal of Educational Psychology, 91, 175189. doi: 10.1037/0022-0663.91.1.175

Rittle-Johnson, B., Fyfe, E. R., \& Loehr, A. M. (2016). Improving conceptual and procedural knowledge: The impact of instructional content within a mathematics lesson. British Journal of Educational Psychology, 86, 576-591. doi: 10.1111/bjep.12124 
Roll, I., Aleven, V., \& Koedinger, K. R. (2011). Outcomes and mechanisms of transfer. In L. Carlson, C. Hölscher, \& T. Shipley (Eds.), Proceedings of the 33rd Annual Conference of the Cognitive Science Society (pp. 2824-2829). Austin: Cognitive Science Society.

Roll, I., Holmes, N. G., Day, J., \& Bonn, D. (2012). Evaluating metacognitive scaffolding in guided invention activities. Instructional Science, 40, 691-710. doi: 10.1007/s11251-0129208-7

Schalk, L., Schumacher, R., Barth, A., \& Stern, E. (2018). When problem-solving followed by instruction is superior to the traditional tell-and-practice sequence. Journal of Educational Psychology. Advance Online Publication. doi: 10.1037/edu0000234

Schmidt, H. G., De Volder, M. L., De Grave, W. S., Moust, J. H., \& Patel, V. L. (1989). Explanatory models in the processing of science text: The role of prior knowledge activation through small-group discussion. Journal of Educational Psychology, 81, 610619.

Schwartz, D. L., \& Bransford, J. D. (1998). A time for telling. Cognition and Instruction, 16, 475-522. doi: 10.1207/s1532690xci1604_4

*Schwartz, D. L., Chase, C. C., Oppezzo, M. A., \& Chin, D. B. (2011). Practicing versus inventing with contrasting cases: The effects of telling first on learning and transfer. Journal of Educational Psychology, 103, 759-775. doi: 10.1037/a0025140

Schwartz, D. L., Lindgren, R., \& Lewis, S. (2009). Constructivism in an age of nonconstructivist assessments Constructivist Instruction (pp. 46-73): Routledge.

Schwartz, D. L., \& Martin, T. (2004). Inventing to prepare for future learning: The hidden efficiency of encouraging original student production in statistics instruction. Cognition and Instruction, 22, 129-184. doi: 10.1207/s1532690xci2202_1 
Schwartz, D. L., Sears, D., \& Chang, J. (2007). Reconsidering prior knowledge. In M. C. Lovett \& P. Shah (Eds.), Thinking with data (pp. 319-344). New York: Routledge.

Sweller, J., \& Cooper, G. (1985). The use of worked examples as a substitute for problem solving in learning algebra. Cognition and Instruction, 2, 59-89.

Sweller, J., Van Merrienboer, J. J., \& Paas, F. (1998). Cognitive architecture and instructional design. Educational Psychology Review, 10, 251-296. doi: 10.1023/A:1022193728205

Toh, P. L. L., \& Kapur, M. (2017). Is having more prerequisite knowledge better for learning from productive failure? Instructional Science, 45, 377-394. doi: 10.1007/s11251-0169402-0

*Van Gog, T., Kester, L., \& Paas, F. (2011). Effects of worked examples, example-problem, and problem-example pairs on novices' learning. Contemporary Educational Psychology, 36, 212-218. doi: 10.1016/j.cedpsych.2010.10.004

VanLehn, K. (1999). Rule learning events in the acquisition of a complex skill: an evaluation of cascade. The Journal of the Learning Sciences, 8, 71-125.

VanLehn, K., Siler, S., Murray, C., Yamauchi, T., \& Baggett, W. B. (2003). Why do only some events cause learning during human tutoring? Cognition and Instruction, 21, 209-249. doi: 10.1207/S1532690XCI2103_01

*Weaver, J. P., Chastain, R. J., DeCaro, D. A., \& DeCaro, M. S. (2018). Reverse the routine: Problem solving before instruction improves conceptual knowledge in undergraduate physics. Contemporary Educational Psychology, 52, 36-47. doi:

10.1016/j.cedpsych.2017.12.003 
Table 1

Summary of Performance Variate Analyses Included in This Review Study

\begin{tabular}{|c|c|c|c|c|c|}
\hline Study & $d$ & $\begin{array}{l}\text { Study } \\
\text { Type }\end{array}$ & Type of Knowledge & $\begin{array}{c}\text { Element } \\
\text { Interactivity }\end{array}$ & $\begin{array}{c}\text { Prior } \\
\text { Knowledge }\end{array}$ \\
\hline $\begin{array}{c}\text { Dubovi } \\
(2018)\end{array}$ & -0.44 & $\begin{array}{c}\text { Journal } \\
\text { Article }\end{array}$ & Procedural & High & Low \\
\hline $\begin{array}{l}\text { Glogger } \\
\text {-Frey } \\
\text { etc. } \\
(2015)\end{array}$ & $\begin{array}{c}-0.72 \\
(\text { Exp. 1) } \\
-0.71 \\
(\text { Exp. 2) }\end{array}$ & $\begin{array}{l}\text { Journal } \\
\text { Article }\end{array}$ & $\begin{array}{l}\text { Procedural } \\
\text { Procedural }\end{array}$ & $\begin{array}{l}\text { High } \\
\text { High }\end{array}$ & $\begin{array}{c}\text { Low } \\
\text { Not } \\
\text { Measured }\end{array}$ \\
\hline $\begin{array}{l}\text { Loibl \& } \\
\text { Rummel } \\
\text { (2014b) }\end{array}$ & $\begin{array}{r}1.33 \\
-0.65 \\
(\text { Exp. 1) } \\
0.66 \\
0.88 \\
(\text { Exp. } 2) \\
\end{array}$ & $\begin{array}{l}\text { Journal } \\
\text { Article }\end{array}$ & $\begin{array}{l}\text { Conceptual } \\
\text { Procedural } \\
\text { Conceptual } \\
\text { Conceptual }\end{array}$ & High & Low \\
\hline $\begin{array}{l}\text { Loibl \& } \\
\text { Rummel } \\
(2014 a)\end{array}$ & $\begin{array}{c}1.67 \\
-0.47 \\
(\text { Exp. 1) } \\
1.35 \\
(\text { Exp. 2) }\end{array}$ & $\begin{array}{l}\text { Journal } \\
\text { Article }\end{array}$ & $\begin{array}{l}\text { Conceptual } \\
\text { Procedural } \\
\text { Conceptual }\end{array}$ & High & Low \\
\hline $\begin{array}{c}\text { Glogger } \\
\text {-Frey } \\
\text { etc. } \\
(2017)\end{array}$ & 0.61 & $\begin{array}{l}\text { Journal } \\
\text { Article }\end{array}$ & Conceptual & Low & High \\
\hline $\begin{array}{c}\text { Chase \& } \\
\text { Klahr } \\
(2017)\end{array}$ & -0.38 & $\begin{array}{l}\text { Journal } \\
\text { Article }\end{array}$ & Procedural & High & Low \\
\hline $\begin{array}{l}\text { Van } \\
\text { Gog } \\
\text { etc. } \\
(2011)\end{array}$ & -0.89 & $\begin{array}{c}\text { Journal } \\
\text { Article }\end{array}$ & Procedural & High & Low \\
\hline $\begin{array}{l}\text { Cook } \\
(2017)\end{array}$ & -0.71 & $\begin{array}{c}\text { Dissert } \\
\text { ation }\end{array}$ & Procedural & High & Low \\
\hline $\begin{array}{l}\text { DeCaro } \\
\& \\
\text { Rittle- } \\
\text { Johnson } \\
(2012) \\
\end{array}$ & 0.35 & $\begin{array}{l}\text { Journal } \\
\text { Article }\end{array}$ & Conceptual & High & Low \\
\hline $\begin{array}{c}\text { Fyfe etc. } \\
(2014)\end{array}$ & $\begin{array}{l}-0.40 \\
-0.39 \\
\end{array}$ & $\begin{array}{c}\text { Journal } \\
\text { Article }\end{array}$ & $\begin{array}{l}\text { Procedural } \\
\text { Conceptual }\end{array}$ & High & Low \\
\hline $\begin{array}{l}\text { Hsu etc. } \\
(2015)\end{array}$ & -0.69 & $\begin{array}{c}\text { Journal } \\
\text { Article }\end{array}$ & Procedural & High & Low \\
\hline
\end{tabular}




\begin{tabular}{|c|c|c|c|c|c|}
\hline $\begin{array}{c}\text { Jacobso } \\
\text { n etc. } \\
\text { (2017) } \\
\end{array}$ & $\begin{array}{l}0.88 \\
0.39\end{array}$ & $\begin{array}{c}\text { Journal } \\
\text { Article }\end{array}$ & $\begin{array}{l}\text { Conceptual } \\
\text { Conceptual }\end{array}$ & High & Low \\
\hline $\begin{array}{l}\text { Lai etc. } \\
(2017)\end{array}$ & 1.45 & $\begin{array}{l}\text { Journal } \\
\text { Article } \\
\end{array}$ & Conceptual & Low & High \\
\hline $\begin{array}{l}\text { Kapur } \\
\text { (2014) }\end{array}$ & $\begin{array}{l}2.00 \\
1.52\end{array}$ & $\begin{array}{l}\text { Journal } \\
\text { Article }\end{array}$ & $\begin{array}{l}\text { Conceptual } \\
\text { Conceptual }\end{array}$ & High & Low \\
\hline $\begin{array}{l}\text { Schwart } \\
\text { z etc. } \\
\text { (2011) }\end{array}$ & $\begin{array}{c}0.66 \\
\text { (Exp. 1) } \\
0.60 \\
\text { (Exp. 2) } \\
\end{array}$ & $\begin{array}{l}\text { Journal } \\
\text { Article }\end{array}$ & $\begin{array}{l}\text { Conceptual } \\
\text { Conceptual }\end{array}$ & High & $\begin{array}{r}\text { Not } \\
\text { Measured }\end{array}$ \\
\hline $\begin{array}{l}\text { Weaver } \\
\text { etc. } \\
(2018)\end{array}$ & $\begin{array}{c}0.27 \\
\text { (Exp. 1) } \\
0.31 \\
\text { (Exp. 2) } \\
\end{array}$ & $\begin{array}{c}\text { Journal } \\
\text { Article }\end{array}$ & $\begin{array}{l}\text { Conceptual } \\
\text { Conceptual }\end{array}$ & High & $\begin{array}{r}\text { Not } \\
\text { Measured }\end{array}$ \\
\hline $\begin{array}{c}\text { DeCaro } \\
\text { etc. } \\
(2015) \\
\end{array}$ & 0.44 & $\begin{array}{c}\text { Journal } \\
\text { Article }\end{array}$ & Conceptual & High & Low \\
\hline $\begin{array}{l}\text { Loehr } \\
\text { etc. } \\
(2014)\end{array}$ & $\begin{array}{c}-1.10 \\
(\text { Exp. 1) } \\
0.69 \\
(\text { Exp. 2) } \\
\end{array}$ & $\begin{array}{l}\text { Journal } \\
\text { Article }\end{array}$ & $\begin{array}{l}\text { Conceptual } \\
\text { Procedural }\end{array}$ & High & Low \\
\hline $\begin{array}{l}\text { Kapur } \\
(2012)\end{array}$ & 1.22 & $\begin{array}{l}\text { Journal } \\
\text { Article }\end{array}$ & Conceptual & High & Low \\
\hline $\begin{array}{l}\text { Kapur } \\
(2010)\end{array}$ & $\begin{array}{l}0.52 \\
0.70 \\
\end{array}$ & $\begin{array}{l}\text { Journal } \\
\text { Article } \\
\end{array}$ & $\begin{array}{l}\text { Conceptual } \\
\text { Conceptual } \\
\end{array}$ & High & Low \\
\hline $\begin{array}{l}\text { Kapur } \\
(2011) \\
\end{array}$ & $\begin{array}{l}0.56 \\
0.55 \\
\end{array}$ & $\begin{array}{c}\text { Journal } \\
\text { Article } \\
\end{array}$ & $\begin{array}{l}\text { Conceptual } \\
\text { Conceptual } \\
\end{array}$ & High & Low \\
\hline $\begin{array}{c}\text { Kapur \& } \\
\text { Bielaczy } \\
\text { c } \\
(2011) \\
\end{array}$ & 0.97 & $\begin{array}{c}\text { Journal } \\
\text { Article }\end{array}$ & Conceptual & High & Low \\
\hline $\begin{array}{c}\text { Kapur \& } \\
\text { Bielaczy } \\
\text { c } \\
(2012) \\
\end{array}$ & 0.68 & $\begin{array}{c}\text { Journal } \\
\text { Article }\end{array}$ & Conceptual & High & Low \\
\hline
\end{tabular}

Note: the negative value shows the superiority of explicit instruction first 